\title{
AS CICATRIZES DA HISTÓRIA E DO MITO EM O GUARANI
}

Evaldo Balbino da Silva Universidade Federal de Minas Gerais

O romantismo foi, seguramente, uma quebra. Levou aos bravios, exóticos, ilimitados horizontes: mas também levou cada povo de volta ao seu próprio passado e à sua natureza específica.

Ernest Fischer

\section{Delimitando o percurso}

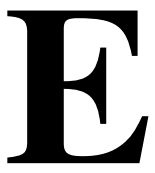

m seu prefácio a Sonbos d'ouro, José de Alencar, discorrendo sobre as três fases do "período orgânico" da literatura brasileira, afirma que o "segundo período é histórico: representa o consórcio do povo invasor com a terra americana" e que a ele "pertencem O Guarani e As Minas de Prata". Ao pontuar que esses livros pertencem ao período histórico, segundo a divisão proposta, Alencar indica que há, nos mesmos, elementos que são "muita e boa messe a colher para o nosso romance histórico". ${ }^{1}$ No entanto, a despeito dessa afirmação, e portanto do projeto do escritor romântico em utilizar-se de seu texto para tratar/representar o momento histórico do novo mundo em que se deu "o consórcio do povo invasor com a terra americana", alguns críticos insistem no fato de que em O Guarani o discurso mítico termina por "apagar" as marcas históricas que imprimiriam ao texto o debate sobre

${ }^{1}$ ALENCAR, 1959. p.697. 
questões sócio-políticas contemporâneas ao período que o autor pretende representar.

Valéria de Marco, na leitura que faz de O Guarani, vê a última cena como um típico "final feliz" de uma história, o qual se enquadraria nos famosos epílogos melodramáticos, tão recorrentes naquele "açucarado romantismo" que parte da tradição crítica tacitamente tem apontado no autor de Cartas sobre a Confederação dos Tamoios. Nessa perspectiva, a autora, após verificar no romance a presença da representação de tensões sócio-políticas e raciais, chega à análise do epílogo e constata que aí o desenrolar do enredo caminha rumo à superação desses mesmos conflitos. E essa superação se dá, segundo a pesquisadora, através da utilização de mitos pelo narrador, para os quais o texto caminha, e os quais, presentes pelas suas cicatrizes, imprimem a idéia de que o texto alencariano procura lançar as bases para a fundação do rosto mestiço do Brasil.

Essa leitura aproxima-se de outras que têm a mesma postura. Araripe Junior diz que em $O$ Guarani o texto leva ao fim das contradições, a partir do momento em que "cai a crosta do goitacás e surge o homem ideal, o amante desanuviado de todos os preconceitos sociais, forte, dessa fortaleza que só possuem as naturezas virginais". ${ }^{2}$

Alfredo Bosi, em Imagens do Romantismo no Brasil, também faz a mesma leitura, resguardando-se, obviamente, as diferenças. $\mathrm{O}$ crítico afirma que, nas páginas finais de O Guarani, cancelam-se

os limites históricos, desfazem-se os contornos da vida em sociedade; e a narração volta-se para as fontes arcanas do romance histórico: a lenda. O homem e a natureza e, entre ambos, a natureza mais humana, a humanidade mais natural, a mulher. O homem deve livrar a mulher da morte pela mediação da natureza protetora. E só no desfecho, em que a vida reflui para a selva salvadora, o romance perfaz a sua ambição de recortar uma comunidade cerrada, "natural".

${ }^{2}$ JUNIOR, 1958. p.168. 
É como se o cronista, leitor de Walter Scott, pusesse a História entre parênteses e imergisse em uma paisagem sem tempo. O passado, substância da crônica, perde celeremente todo peso. ${ }^{3}$

Longe de negar a mestiçagem apontada por de Marco, para a qual o mosaico mítico do texto de Alencar aponta, o presente trabalho a reconhece. No entanto, a partir de uma leitura diferenciada das citadas acima, o objetivo aqui é entender a forma como coexistem na trama de O Guarani as malhas mítica e histórica, sem que uma seja superada pela outra. Nesse sentido, considera-se aqui a vocação histórica e sociológica do Romantismo, tão bem apontada por Antonio Candido. Segundo o autor de Formação da Literatura Brasileira, a escola romântica estimulou

o interesse pelo comportamento humano, considerado em função do meio e das relações sociais. Ora, o estudo das sucessões históricas e dos grupos sociais, da rica diversificação estrutural de uma sociedade em crise, não cabia de modo algum na tragédia ou no poema: foi a seara própria do romance, que dela se alimentou, alimentando ao mesmo tempo o espírito histórico do século. ${ }^{4}$

\section{As malhas míticas e históricas na tessitura do romance histórico}

Sem deixar de alimentar o espírito histórico do século, a escola romântica, e isso se deu nos seus autores mais representativos, voltou-se para o mito. Como, então, mito e História se relacionam, sem que as marcas desta sejam elididas? Isso é bem explicado por Eudoro de Sousa, quando ele afirma que uma comunidade fundase, ou tem fundamento, no símbolo, ou sistema de símbolos, que lhe é comum. Sendo assim, uma comunidade a si mesma se contempla no seu antigo símbolo originário. "Este, porém, reside no passado

${ }^{3}$ BOSI, 1987. p.242.

${ }^{4}$ CANDIDO, 1957. p.110. 
de todos os passados, a uma distância além da maior de todas as distâncias, além de onde já não há hora que não seja outra, a outra hora que soa para o tão longe em que se perdeu o mais dilatado afastamento." 5

Para contemplar-se no antigo símbolo que a origina, a comunidade há de voltar-se, então, "para aquele passado que é mais do que distante, que é passado longínquo e de outra hora”. Já que, segundo Sousa, a História é a expressão da presença do presente e que o mito é a expressão da presença daquele passado longínquo, situado antes da História, esta anda à mercê do mito, na medida em que se quer designar aquilo que se constituiu somente nos tempos primordiais. ${ }^{6}$ Dessa forma, considerando que os românticos, ao mesmo tempo em que ancorados no seu momento histórico, voltavam-se para um passado mítico e, portanto, remoto, percebemos a instauração de um duplo movimento, no qual misturam-se a busca de uma harmonia anterior e a consciência das fragmentações e antinomias modernas.

... enquanto buscavam [os românticos] na distância do tempo ou do espaço a unidade e inocência, realçavam ao mesmo tempo o esfacelamento, a fragmentação, o homem-espelho, desdobrado em reflexos, o homem-máscara, o duplo, o sósia, o homem que vendeu a alma, o homem que vendeu a sombra e perdeu e estabilidade, a raiz, a "pátria", exilado que é da unidade paradisíaca."

Assim, nas linhas de Alencar pulsam marcas histórico-sociais, "o esfacelamento", que remontam ao processo de colonização das terras brasileiras e de aculturação dos indígenas. Na casa de Antônio de Mariz, situada às margens do Paquequer, afirma Valéria de Marco, apresentam-se tensões que ameaçam o projeto de fundação da brasilidade. De fato, é ali, naquela comunidade fundada no interior das matas brasileiras, no século XVII, que se afloram jogos de

\footnotetext{
5 SOUSA, 1981. p.7.

${ }^{6}$ SOUSA, 1981. p.18.

${ }^{7}$ ROSENFELD, 1987. p.161.
} 
interesses entre os próprios colonizadores. Nesse aspecto, verificase a rebelião dos aventureiros que viviam sob as ordens de D. Antônio de Mariz, numa relação de lealdade que nos remete aos tempos de cavalaria da Idade Média.

Ainda, detectando as tensões presentes no solar dos Mariz, devemos nos lembrar da questão racial que vislumbramos na voz do narrador alencariano, a partir do momento em que ele, por exemplo, contrasta as personagens Cecília e Isabel. A primeira, loura, típica mulher européia inserida nos trópicos, é a filha naturalizada de D. Antônio e D. Laureana. Já a segunda é a mulher brasileira, filha bastarda de D. Antônio com uma índia, sendo, portanto, fruto da mestiçagem. Dessa forma, temos, na voz do narrador, as seguintes descrições que contrastam, respectivamente, Cecília e Isabel:

Os lábios vermelhos e úmidos pareciam uma flor da gardênia dos nossos campos, orvalhada pelo sereno da noite, o hálito doce e ligeiro exalava-se formando um sorriso. Sua tez alva e pura como um froco ( $\mathrm{sic}$ ) de algodão, tingia-se nas faces de uns longes cor-de-rosa, que iam desmaiando, morrer no colo de linhas suaves e delicadas. ${ }^{8}$

Era um tipo inteiramente diferente do de Cecília; era o tipo brasileiro em toda a sua graça e formosura, com o encantador contraste de languidez e malícia, de indolência e vivacidade.

Entretanto, a tensão entre raças não reside simplesmente nessas duas descrições que faz o narrador, mas antes se nos apresenta em todo o transcorrer da narrativa. Ela, na verdade, explicita-se num diálogo entre Cecília e Isabel, em que esta desabafa contra o desprezo a que é submetida por ser uma mestiça. É importante observarmos que o desabafo de Isabel, pelo fato de ela viver "na escala intermediária entre o branco que domina e o selvagem escravizado", ${ }^{10}$ não é tão-somente um ressentimento pela

\footnotetext{
${ }^{8}$ ALENCAR, 1977. p.24.

9 ALENCAR, 1977. p.25.

${ }^{10}$ MARCO, 1993. p.77.
} 
sua condição, mas também uma denúncia da relação entre o colonizador "civilizado" e o índio que, equiparado a um animal, é submetido à escravidão. É o que podemos perceber no diálogo transcrito abaixo, no qual ambas as personagens referem-se a Peri.

- Prima, disse a moça com um ligeiro tom de repreensão, tratas muito injustamente esse pobre índio que não te fez mal algum.

- Ora, Cecília, como queres que se trate um selvagem que tem a pele escura e o sangue vermelho? Tua mãe não diz que um índio é um animal como um cavalo e um cão?

(...)

- Sei que tu não pensas assim, Cecília; e que o teu bom coração não olha a cor do rosto para conhecer a alma. Mas os outros?...Cuidas que não percebo o desdém com que me tratam? ${ }^{11}$

Ao analisarmos as palavras de Isabel, não devemos cair na ingenuidade de dizer que, ao colocá-las na boca desta personagem, o narrador quis fazer de Cecília aquela heroína situada além dos preconceitos, quando, na verdade, ela os tem. Pois o que são os sonhos desta linda e loura moça se não o simples contraponto entre um lindo cavalheiro e um selvagem? Uma oposição que na realidade a fere, mas que por isso não deixa de existir:

Ela sonhava que uma das nuvens brancas que passavam pelo céu anilado, roçando a ponta dos rochedos, se abria de repente: e um homem vinha cair a seus pés tímido e suplicante. (...)

Com o seio palpitante, toda trêmula e ao mesmo tempo contente e feliz, abria os olhos; mas voltava-os com desgosto, porque, em vez do lindo cavalheiro que ela sonhara, via a seus pés um selvagem. ${ }^{12}$

Mesmo que Alencar não tenha, neste livro, enfocado a sociedade escravocrata de sua época, como procura mostrar Valéria de Marco ao dizer que nas páginas iniciais o narrador enfatiza o termo "vassalo", sobrepondo-o a outro, "escravo", ${ }^{13}$ não podemos

\footnotetext{
${ }^{11}$ ALENCAR, 1977. p.26.

12 ALENCAR, 1977. p.25.

${ }^{13}$ MARCO, 1993. p.24.
} 
negar a preocupação histórica do texto. Este, como vimos, aponta constantemente para os tempos da matéria narrativa, já que os conflitos aí encenados não deixam de ser, também, representação do complexo universo de relações instauradas aqui no Brasil, no século XII, entre estrangeiros, índios e mestiços. Além disso, ao verificarmos a inserção de narrativas míticas no tempo histórico abordado por Alencar, devemos compreender que, utilizando-se as palavras de Mirceia Eliade, "em suma, os mitos descrevem as diversas, e algumas vezes dramáticas, irrupções do sagrado (ou do 'sobrenatural') no Mundo. É essa irrupção do sagrado que realmente fundamenta o Mundo e o converte no que é hoje". ${ }^{14}$

Eis, então, uma das peculiaridades do mito: mesmo que fale de um passado distante, ele estará sempre dizendo do agora (no caso, o momento histórico de que trata o romance), porque justamente procura explicar aquilo que fundamentou o mundo e o converteu no que é hoje.

Sendo assim, não podemos negar o caráter histórico de $O$ Guarani, já que em suas páginas encontram-se representações de um momento histórico (passado, em relação à época do autor) bem definido. Não podemos, por outro lado, exigir de Alencar a "razoável preocupação com a fidelidade histórica”, que Volobuef diz ser necessária num romance histórico. ${ }^{15} \mathrm{E}$ isso, por dois motivos: primeiro, porque a Literatura não precisa prender-se nas malhas da verdade histórica, ${ }^{16}$ mas sim se preocupar com sua coerência interna, dentro daquele mundo que ela mesma cria; segundo, pelo fato de que Alencar, poeta do romance, nos termos de Augusto Meyer, romanceava tudo. ${ }^{17}$ Assim, romancista histórico, na esteira de

\footnotetext{
${ }^{14}$ ELIADE, 1972. p.11.

${ }^{15}$ VOLOBUEF, 1999. p.50.
}

${ }^{16}$ Na verdade, nem da própria Historiografia podemos exigir uma "verdade", no sentido primeiro do termo, pois toda e qualquer análise histórica não deixa de ser uma leitura de determinado indivíduo, considerando-se este como sujeito que, com sua mundivisão, tem uma forma de interpretação particular.

${ }^{17}$ MEYER, 1964. p.13. 
Walter Scott, ele se destaca por interpretar livremente os documentos históricos, pondo às soltas sua imaginação, elemento tão caro à escola romântica. Daí a idealização extrema, tanto das personagens históricas, como é o caso de D. Antônio, quanto da natureza, palco do enredo romanesco.

\section{As cicatrizes da História}

Em meio aos conflitos instaurados no Paquequer, soma-se outro: a sede de vingança dos Aimorés, devido à morte de uma de suas índias por mãos de D. Diogo, filho de D. Antônio. A casa dos Mariz, após a invasão da tribo vingadora, termina em ruínas. Tanto o fogo inimigo, quanto aquele produzido pelo próprio depósito de pólvora de D. Antônio, destroem o solar completamente. O epílogo do romance se abre justamente com a descrição desse resultado catastrófico.

Quando o sol, erguendo-se no horizonte, iluminou os campos, um montão de ruínas cobria as margens do Paquequer. Grandes lascas de rochedos, talhadas de um golpe e semeadas pelo campo, pareciam ter saltado do malho gigantesco de novos ciclopes.

A eminência sobre a qual estava situada a casa tinha desaparecido, e no seu lugar via-se apenas uma larga fenda semelhante à cratera de algum vulcão subterrâneo.

As árvores arrancadas dos seus alvéolos, a terra revolta, a cinza enegrecida que cobria a floresta, anunciavam que por aí tinha passado algum desses cataclismas que deixam após si a morte e a destruição. ${ }^{18}$

A partir dessa catástrofe, o narrador abandona o solar dos Mariz e centra sua observação em Peri e Ceci, que descem numa canoa pelas águas do Paquequer. Após salvar Ceci das chamas do solar, o índio leva-a para a floresta, protegendo-a a todo instante. Posteriormente, quando ambos já estão descendo pelo Rio Paraíba,

${ }^{18}$ ALENCAR, 1977. p.204. 
as águas arrebentam, e Peri, ainda num ato heróico, toma "Cecília meio adormecida nos seus braços e galga o cimo de uma palmeira". Quando esta se aproxima da iminência de submergir-se, o índioherói arranca-a, e a mesma, arrastada pela torrente impetuosa, segue sobre as águas furiosas e some-se no horizonte.

Como já mencionamos, no que diz respeito a esta cena final de O Guarani, a tradição crítica, apoiando-se no idílio amoroso aí instaurado, considera-a como a representação de um mundo idealizado, permeado pelo mítico e longe das marcas históricas, onde não há lugar para a morte inglória e onde o amor impera, mesmo em pleno dilúvio. Entretanto, um primeiro aspecto, que já problematizaria essa leitura, é o fato de que o idílio é apenas insinuado pelo narrador, mas não concretizado, devido ao recurso estilístico da comparação, utilizado para descrever a languidez com que Cecília se deixa nos braços de Peri, reclinando "a loura fronte". ${ }^{19}$ O próprio Araripe, mesmo defendendo a superação das contradições no romance, não deixa de perceber que, a despeito da idealização instaurada no seu epílogo, este é "vago e vaporoso". Somando-se a esse caráter vago, há de se considerar que, mesmo transplantando o enredo para o espaço da natureza, idealizado ao extremo, o narrador de Alencar ainda faz entreverem-se, nas linhas do texto, as tensões sociais presentes à época da aculturação dos indígenas.

Valéria de Marco vê nos mitos bíblicos e indígenas, utilizados por Alencar nesta última parte do seu livro, a mesma função que eles desempenham nos contextos de que foram tirados, ou seja, a de restaurarem uma unidade e harmonia perdidas no curso da História. E isso a estudiosa faz com vistas a comprovar que o romance caminha para um final feliz e conciliador. No entanto, se essa é a função primeira de todo mito, este, ao ser utilizado pelo romântico, além de apontar para a unidade original entre homem e universo,

19 "... os lábios abriram como as asas purpúreas de um beijo soltando o vôo". ( ALENCAR, 1977. p.220). 
também sugere a insatisfação com que o romântico via o momento histórico presente, com suas contradições e adversidades. Na esteira do pensamento de Schiller, podemos considerar a diferença entre o poeta ingênuo, aquele que se expressa na sua naturalidade por ainda ser natureza, e o poeta sentimental, aquele que já entrou na cultura e perdeu a unidade anterior, natural, e que por isso expressa, não a realidade (natureza) como ela é, mas como deveria ser, ou seja, expressa-a como ela era (e isso ele pressupõe) antes de ser corrompida pela cultura. Nesse sentido, diante da natureza ideal, duas serão as posturas do poeta sentimental: ou elegíaca ou satírica. ${ }^{20}$ Assim, se por um lado José de Alencar constrói com as penas da idealização um espaço mítico nas matas do Brasil, fazendo-lhe uma apologia, por outro ele ainda nos remete aos elementos da cultura que, longe de serem constituintes do paraíso encenado, a este se opõem.

Nessa perspectiva, devemos rever como funcionam, dentro do romance, o incêndio da casa dos Mariz e o dilúvio das águas do Paraíba.

\subsection{E o fogo purifica o quê?}

Consideramos que o incêndio ocorrido no Paquequer nos remete ao mito apocalíptico do fogo, o qual transcrevemos parcialmente a seguir.

E vi descer do céu um anjo, que tinha a chave do abismo, e uma grande cadeia na sua mão.

Ele prendeu o dragão, a antiga serpente, que é o Diabo e Satanaz, e amarrou-o por mil anos.

(...)

E, acabando-se os mil anos, Satanaz será solto da sua prisão,

E sairá a enganar as nações que estão sobre os quatro cantos da terra, Gogue e Magogue, cujo número é como a areia do mar, para as ajuntar em batalha.

E subiram sobre a largura da terra, e cercaram o arraial dos santos e a cidade amada; mas desceu fogo do céu, e os devorou." ${ }^{21}$

${ }^{20}$ SHILLER, 1987. p.47-49.

${ }^{21}$ BÍBLIA SAGRADA, 1991. p.297. 
Analisando o texto do Apocalipse, vemos que o fogo do "último dia" tem pontos em comum com o incêndio da casa dos Mariz. Dessa forma, há uma certa equivalência entre os Aimorés que atacam o solar e o exército de Satanás que rodeia e ataca a "cidade amada". Loredano, o padre sacrílego e desencadeador da revolta dos aventureiros, é preso antes de ser queimado, tal como ocorre ao próprio Diabo. O ataque dos Aimorés deve-se a um "desvio" de D. Diogo que matou uma índia aimoré, e o fogo eterno destina-se àqueles que também cometem "desvios".

Entretanto, apesar de haver similaridades entre o mito bíblico e a ficção alencariana, não há como deixar de apontar aspectos que instauram oposições entre os dois textos. A primeira diferença que refuta qualquer identidade é o fato de que enquanto o fogo bíblico emana somente da virtude ("céu"), o incêndio do solar se origina tanto da virtude (O depósito de pólvora explodido por D. Antônio, pois ele representa os valores cristãos e, portanto, a autoridade máxima do bem no solar.), quanto da maldade, que é representada pelos Aimorés e suas setas inflamadas. Ainda mapeando as diferenças em análise, discordamos de Valéria de Marco, quando ela afirma que em O Guarani "o fogo cumpriu sua função no ritual de purificação", uma vez que "ele expurgou o mal e apurou a virtude. Ela está em sua inteireza na canoa que desliza pelo rio onde contrasta com o caos produzido pelo conflito e com a fenda aberta na paisagem." ${ }^{.22}$

Realmente o fogo bíblico é o instrumento da purificação total utilizado pelas forças do bem. Mas, se podemos, por um lado, identificar Ceci e Peri com a virtude, por outro, é impossível afirmarmos que o incêndio do solar procedeu a uma completa purificação das tensões antes existentes, como faz crer Valéria de Marco. Enquanto no Apocalipse o fogo culminará num mundo metafísico, onde reinará a virtude e onde o plano material cessará; no romance alencariano a destruição da casa dos Mariz desemboca num mundo metafísico para os que morreram no incêndio e,

${ }^{22}$ MARCO, 1993. p.85. 
diferentemente do que afirma De Marco, dentro da canoa dá-se a continuidade do mundo terreno. Neste, apesar de idealizado, permanecem as tensões raciais e religiosas, uma vez que seguem rio abaixo uma mulher civilizada e um selvagem semicivilizado. No que se refere à cristianização de Peri, este não se converteu à Cruz Sacrossanta, uma vez que somente aceitou que D. Antônio o batizasse no intuito de receber a permissão para salvar Ceci:

- Peri é um selvagem, disse o índio tristemente; não pode viver na taba dos brancos.

- Por quê? Perguntou a menina com ansiedade. Não és tu cristão como Ceci?

- Sim, porque era preciso ser cristão para te salvar; mas Peri morrerá selvagem como Ararê. ${ }^{23}$

Ainda, Cecília somente adquire consciência do amor que tem por Peri, quando ele não está mais no mundo civilizado, mas nas matas; e aqui não há mais meios de ela confrontá-lo com um cavalheiro, pois os que o eram de fato já foram consumidos pelo fogo. Peri, mesmo dotado de um cavalheirismo que a pena idealizadora de Alencar erigira, não deixa de trazer em si elementos da cultura aborígine. É o que se diz no momento em que o narrador assume o ponto de vista de Cecília:

No meio de homens civilizados, era um índio ignorante, nascido de uma raça bárbara, a quem a civilização repelia e marcava o lugar de cativo. Embora para Cecília e D. Antônio fosse um amigo, era apenas um amigo escravo.

Aqui, porém, todos as distinções desapareciam; o filho das matas, voltando ao seio de sua mãe, recobrava a liberdade; era o rei do deserto, o senhor das florestas, dominando pelo direito da força e da coragem. ${ }^{24}$

Por fim, ainda com relação à ausência de uma purificação completa por parte do incêndio no Paquequer, temos a iniciativa de

${ }^{23}$ ALENCAR, 1977. p.212.

${ }^{24}$ ALENCAR, 1977. p.209. 
Cecília em querer permanecer ao lado de Peri. Porém, ela, em última instância, pertence à civilização que, ao contrário do que ocorre no mito bíblico que destruirá completamente o mundo material, não é expurgada juntamente com a casa dos Mariz. Em outras palavras, o fogo, em $O$ Guarani, não aponta para a eternidade paradisíaca do cristianismo, mas para uma continuidade do plano terreno que, mesmo instaurando-se num espaço paradisíaco, mítico, o da mata virgem brasileira, não deixa de ser perpassado por contradições que ainda são, em última instância, as cicatrizes históricas advindas do processo de colonização do Brasil. As marcas da civilização ainda coexistem com o espaço mítico. Portanto, caso haja talvez uma interferência da sociedade na relação de Peri e Ceci, a possibilidade desse amor idílico, que só é possível de se realizar longe do mundo civilizado, cairá certamente por terra.

\section{As águas incertas e as portas abertas do futuro: a modernidade em $O$ guarani}

Valéria de Marco afirma que, no dilúvio vivenciado por Ceci e Peri, o amor vence as águas, e o texto caminha rumo à fundação do rosto mestiço do país, o que se dá paulatinamente com a superação de todos os conflitos. Para defender esse caminhar da narrativa rumo à mestiçagem, a autora considera que o narrador

reúne todos as forças e muda o destino de Peri, dando a ele missão mais elevada: a de reviver o mito do dilúvio, conjugando os tempos imemoriais dos nativos e dos descobridores, e fundar o rosto mestiço do país. ${ }^{25}$

Aqui, mais uma vez, discordamos da idéia de que Peri e Ceci simplesmente "reviveram o mito do dilúvio", já que este ganha, nas terras brasileiras pintadas por Alencar, uma outra face. O texto alencariano faz referência explícita ao mito indígena do dilúvio,

${ }^{25}$ MARCO, 1993. p.86. 
através da narração de Peri a Ceci, e também ao mito do dilúvio bíblico, porém implícita neste caso. Se analisarmos tanto um quanto o outro, verificamos que os dois culminam na continuidade da existência temporal, uma vez que Tamanduaré e Noé, com suas respectivas famílias, retornaram à terra após o dilúvio ter acabado, e tornaram a povoá-la. Isso, entretanto, não acontece com as duas personagens de Alencar que sobreviveram ao incêndio do Paquequer. Mesmo que Peri tenha contado o mito de Tamanduaré e exposto seu final feliz, isso não quer dizer que necessariamente ele e Ceci terão o mesmo fim, porquanto a palmeira em que ambos estão segue indefinidamente sobre as águas, instaurando-se uma cena que, sendo a última do livro, não finaliza o enredo, por ser "vaga e vaporosa", para se utilizarem os já referidos termos de Araripe Junior.

Não se trata aqui de procurar um fechamento mais trágico para O Guarani. Não estamos considerando o fato de Cecília, já na última cena, dizer a Peri que ambos viverão "lá no céu, no seio de Deus", porque ela, sendo também uma personagem, não vê perspectivas de salvar-se na imensidão daquelas águas. Suas palavras não nos servem enquanto previsão de algo que vai acontecer. O que nos resta é somente a palmeira deslizando sobre as águas furiosas.

A palmeira arrastada pela torrente impetuosa fugia...

E sumiu-se no horizonte... ${ }^{26}$

Observemos que o romance, longe de fechar-se no "enlace de um casal de apaixonados", para se usarem as palavras de Volobuef ao referir-se aos finais felizes do romantismo brasileiro, ${ }^{27}$ constróise como texto que culmina numa abertura de leituras, instaurando, portanto, não uma verdade única e atemporal, mas possibilidades para um caminho em contínuo fazer-se. Alencar, nesse sentido, expressa bem a consciência romântica da infinitude, do paraíso perdido irremediavelmente - expressão da consciência da perda, na

\footnotetext{
${ }^{26}$ ALENCAR, 1977. p.220.

${ }^{27}$ VOLOBUEF, 1999. p.76.
} 
medida em que, mesmo criando, pelo mito, um paraíso nas matas virgens, sabe-se ainda preso às contingências que vão negando a todo momento esse mesmo paraíso erigido pelas asas da imaginação. É também nesse sentido que O Guarani insere-se na postura romântica de busca constante, como que num movimento infindavelmente retilíneo. Num trajeto que não se finda, diz-nos Nivelle, "o romantismo está marcado pela turbulência e pelo desassossego, pois sente a insatisfação de quem nunca alcança o que procura" ${ }^{28} \mathrm{Como}$ corolário, a obra romântica constrói-se num permanente fazer-se, rumo a um ponto inatingível. Daí seu caráter de abertura. E assim é o movimento no texto alencariano, pois as forças contrárias vão sempre surgindo e o índio-herói vai sempre as vencendo. Episódios vão se sucedendo, numa ânsia interminável e, naquele que seria o último momento, o texto não se interrompe, abrindo-se nas reticências, estendendo-se sempre para frente.

Esse voltar-se permanentemente para o futuro, segundo Octavio Paz, caracteriza a modernidade crítica, uma vez que "o homem moderno se vê lançado para o futuro com a mesma violência com que o cristão se via lançado para o céu ou para o inferno". Nosso futuro, continua Paz, "não é um lugar de repouso, não é um fim; ao contrário, é um contínuo começo, um permanente ir para mais além. Nosso futuro é um paraíso/inferno; paraíso, por ser o lugar de eleição do desejo, inferno, por ser o lugar da insatisfação". ${ }^{29}$

Assim é a modernidade na qual se insere O Guarani. Tanto o olhar deste, quanto o daquela, lançam-se constantemente para um futuro que não é, mas que está lá, como um horizonte aberto, para o qual se arrasta a água da vida, levando consigo sonhos, desilusões, enfim, possibilidades para um mundo multifacetado em que o indivíduo se enxerga. Retomar os mitos, as origens, já não é mais querer ingenuamente o primitivo, o puro já irremediavelmente

${ }^{28}$ Cf. VOLOBUEF, 1999. p.129.

${ }^{29}$ PAZ, 1984. p.51. 
perdido, mas, antes, se trata de um novo saber, uma inocência sábia (e aí temos a criança irônica de Novalis), porque impregnada de uma consciência - a de que os castelos reerguidos são uma possibilidade, mas não deixam de ser de areia. Nessa perspectiva, a busca do mito é sede de unicidade, de paraíso, mas é ao mesmo tempo, e justamente, a procura de se estabelecerem possíveis caminhos futuros sem nenhuma ingenuidade. Que a palmeira prossiga, que bata ou não contra um obstáculo, que vire ou não sobre as águas; mas que prossiga rumo ao horizonte sem fim do futuro.

\section{Referências Bibliográficas}

ALENCAR, José de. O Guarani. 7.ed. São Paulo: Ática, 1977.

ALENCAR, José de. Bênção paterna. Prefácio a Sonbos d'ouro. In: Obra completa. Rio de Janeiro: Aguilar, 1959. v.1, p.691-702.

BÍBLIA SAGRADA. Gênesis e Apocalipse. Trad. João Ferreira de Almeida. 1991.

BOSI, Alfredo. Imagens do Romantismo no Brasil. In: GUINSBURG, J. (Org.) O Romantismo. São Paulo: Perspectiva, 1985. p.239-256. CANDIDO, Antonio. Um instrumento de descoberta e interpretação. In: Formação da literatura brasileira. São Paulo: Martins, 1957. p.109-118.

ELIADE, Mirceia. Mito e realidade. São Paulo: Perspectiva, 1972.

JUNIOR, Araripe. José de Alencar. Obra crítica. Rio de Janeiro: Casa de Rui Barbosa, 1958. p.129-258.

MARCO, Valéria de. O Guarani: as cicatrizes do mito. In: A perda das ilusões, o romance histórico de José de Alencar. Campinas: Editora da UNICAMP, 1993.

MEYER, Augusto. Alencar e a tenuidade brasileira. In: ALENCAR, José de. Obra completa. Rio de Janeiro: Aguilar, 1964. v.2, p.1124. 
PAZ, Octavio. A revolta do futuro. In: Os filhos do barro. Rio de Janeiro: Nova Fronteira, 1984.

SCHILLER. Sobre poesia ingênua e poesia sentimental. In: LOBO, Luíza. Teorias poéticas do Romantismo. Porto Alegre: Mercado Aberto, 1987.

SOUSA, Eudoro de. História e mito. Brasília: Editora Universidade de Brasília, 1981.

VOLOBUEF, Karin. Romantismo alemão. In: Frestas e arestas: a prosa de ficção do Romantismo na Alemanha e no Brasil. São Paulo: Fundação Editora da UNESP (FEU), 1999.

\section{Resumo}

Este artigo busca analisar, através do romance O Guarani, de José de Alencar, como mito e História coexistem nas malhas textuais da literatura romântica.

\section{Resumen}

Este artículo pretende analizar, utilizando el libro O Guarani, de José de Alencar, como mito e Historia coexisten en las mallas textuales de la literatura romántica. 